\title{
Rhinophototherapy in chronic rhinosinusitis: a double blind randomized placebo-controlled trial*
}

\author{
Nicolas Dulguerov', Nils Guinand', Delphine Courvoisier², Basile Nicolas \\ Landis' ${ }^{1}$, Jean-Silvain Lacroix ${ }^{3}$, Conrad Hauser ${ }^{4}$ \\ 'Department of Oto-Rhino-Laryngology Head and Neck Surgery, Geneva University Hospital, Geneva, Switzerland \\ 2 Division of Oral and Maxillofacial Surgery, Geneva University Hospital, Geneva, Switzerland \\ ${ }^{3}$ Faculty of medicine, Geneva Medical University, Geneva, Switzerland \\ ${ }^{4}$ Private practice, Geneva, Switzerland
}

Rhinology 55: 106-112, 2017

https://doi.org/10.4193/Rhino16.063

*Received for publication:

February 13, 2016

Accepted: June 14,2016

\begin{abstract}
Background: This study evaluated the efficacy of rhinophototherapy in patients with chronic rhinosinusitis (CRS) without nasal polyps.

Method: In this randomized double-blind, placebo-controlled trial, CRS patients $(n=50)$ received either mixed visible and ultraviolet (UVA and UVB) light source application (mUV/VIS) or visible light alone that served as placebo. Both groups were treated for 3 weeks.
\end{abstract}

Results: Results in the rhinophototherapy and placebo group were not significantly different and failed to reduce patient-reported outcomes measures (Rhinosinusits Disability Index, Visual Analogic Scale of symptom severity) and objective scores (rhinomanometry, olfactory thresholds, nasal Nitic Oxide concentrations), immediately and one month after treatment.

Conclusions: The present data suggest that rhinophototherapy is not an efficient treatment for chronic rhinosinusitis without nasal polyps.

Key words: rhinophototherapy, chronic rhinosinusitis, trial, UV-A, UV-B

\section{Introduction}

Chronic rhinosinusitis (CRS) is a frequent disease affecting 5 to $15 \%$ of the population in the USA and Europe ${ }^{(1)}$. Its impact on the physical and psychosocial functioning of the affected population has become a public health issue. The socioeconomic impact of CRS is estimated at 5.7 billion dollars per year in the USA, with $56 \%$ due to direct costs and $46 \%$ due to absenteeism and disability ${ }^{(2)}$. The cornerstones of the treatments in CRS are topical steroids, nasal saline, oral steroids and long-term oral antibiotics therapy. However, only roughly half of the patients receiving medical treatment will achieve symptomatic control with the remaining patients becoming potentially candidates for functional endoscopic surgery ${ }^{(3)}$. Having said this, it is needless to stress the fact that alternative medical treatments for CRS are urgently needed.

The diagnosis of CRS is given with a very broad common deno- minator of symptoms and radiologic or endoscopic pathological findings as described in the EPOS paper ${ }^{(4)}$. The clinical presentation is unspecific and it is assumed that CRS itself has many different more specific underlying causes of which many are not yet known or not fully understood. Diverse CRS classifications based on histological analysis, involved cytokine profiles, type of immune response or underlying allergies and presence (CRSwNP) or absence (CRSsNP) of polyps have been proposed ${ }^{(5-7)}$. These efforts to better understand CRS subtypes have however not yet fundamentally changed the fact that topical nasal steroids are the most prevalent end efficient treatment for most CRS forms ${ }^{(8,9)}$. Ultraviolet radiation (UVR) has many biologic effects on the skin and UVR phototherapy has developed along the production of different light sources ${ }^{(8)}$. The UV spectrum is sub-divided in 3 ranges: UVC (200-290 nm), UVB (290-320 nm) and UVA (320-400 nm), with UVB and UVA having medical indi- 
cations. The energy of the light is absorbed by molecules, called chromophores that become photoproducts after undergoing a photochemical reaction. Those photoproducts undergo a repair mechanism, are toxic to the cell or initiate a signal transduction pathway ${ }^{(9)}$. Immune-mediated disease of the skin such as atopic dermatitis and psoriasis are efficiently treated with phototherapy. There is a profound immunosuppressive effect with reduction of Langerhans cell number and function, induction of apoptosis in infiltrating $T$ cells, and induction of immune-modulatory cytokines such as TNF- $\alpha$ and IL-10 (10).

Koreck et al. were the first to study intra-nasal phototherapy (11). They demonstrated that intranasal irradiation with low doses of UV-B (5\%), UV-A (25\%) and visible light (70\%), so called mixed ultraviolet and visible light (mUV/VIS), at a dose of $1.6 \mathrm{~J} / \mathrm{cm}^{2}$ (starting dose) to $2.6 \mathrm{~J} / \mathrm{cm}^{2}$ (maximal dose) for 9 sessions, reduced the number of eosinophils, eosinophilic cationic protein (ECP) and IL-5 in patients with ragweed allergic rhinitis in vivo. Also, mUV/VIS irradiation induced a dose-dependent increase in apoptotic eosinophils and T cells. Clinically, they studied the effect of intranasal mUV/VIS (rhinophototherapy) on patients with allergic rhinitis and they showed an improvement in total nasal score, measuring nasal obstruction, sneezing, rhinorrhea and nasal itching, compared to placebo ${ }^{(11)}$. They also studied the effect of narrow-band UVB three times a week for 12 weeks at a dose of $0.3-1.2 \mathrm{~J} / \mathrm{cm}^{2}$ on patients with CRSwNP demonstrating a reduction of visual analog nasal obstruction score and NOSE quality of life score compared to baseline ${ }^{(12)}$.

The potential carcinogenetic risk of rhinophototherapy on the nasal mucosa seems to be small. A major issue in the early days of rhiophototherapy was the risk of inducing cancer by exposing mucosa to UVB light. It is well known that excessive sunlight exposure is associated with increased risk of skin cancer development in exposed body areas. Based on a literature review, Lee reported that UVB phototherapy remains a very safe treatment modality without evidence of increased skin cancer risk ${ }^{(13)}$. In patients with psoriasis who received UVB in addition to PUVA (UVA plus a photosensitising drug), a regimen with known elevated skin cancer risk, non-melanoma skin cancer was significantly elevated in 1 study but not in 2 others ${ }^{(13)}$. A recent followup study from 2005 confirmed the increased non-melanoma skin cancer risk in a population with psoriasis and less than 100 PUVA treatments and more than 300 UVB treatments but not in subjects with $<300$ UVB treatments ${ }^{(14)}$. From these studies it can be concluded that there is no evidence of increased risk for skin cancer development in humans associated with UV light treatment, except possibly in patients with PUVA treatment who had >300 UVB treatments. On nasal tissue samples before and at different times after rhinophototherapy, it has been shown that UV-induced DNA damage response of respiratory epithelia is very similar to that of the human epidermis and that nasal mucosa is able to efficiently repair UVB induced DNA damages ${ }^{(15)}$.
Because rhinophototherapy has been shown to be efficacious in ragweed allergic rhinosinusitis and on patients with nasal polyps, we investigated whether patients with CRS without NP may also benefit from rhinophototherapy. The aim of this study was to compare the efficacy of endonasal exposure to a mixed visible and ultraviolet (UVA and UVB) light source (mUV/VIS) with visible light alone in 50 patients with CRSsNP in a randomised, double-blind placebo-controlled study.

\section{Materials and methods}

Patients, randomization and procedure

We performed a prospective triple (patient, investigators, and statistician) blind randomized placebo controlled trial study to evaluate the clinical benefit of intranasal mUV/VIS phototherapy at Geneva University Hospital. Patients diagnosed with chronic rhinosinusitis (CRS) according to the EPOS document published by the European Academy of Allergy and Clinical Immunology, were offered to participate to the study.

Inclusion criteria were the presence of 2 CRS symptoms for more than 12 weeks associated with one or more endoscopic findings of polyps, mucopurulent discharge from middle meatus, mucosal obstruction in middle meatus, or presence of mucosal change on sinus CT. Age between 18 and 65 years was also required. The study was approved by the Geneva University Hospital ASPIC ethic committee (05-129 NAC 05-045). The Consolidated Standards of Reporting Trials (CONSORT) flowchart (Figure 1) and checklist (Appendix 1) were followed.

Exclusion criteria were acute exacerbation of CRS defined by the presence of two of the following symptoms: fever, headache, painful pharyngitis, and positive bacterial sampling. Also evidence of acute bacterial or viral infection of the nose, structural abnormalities, stage 2 or 3 nasal polyps, medicamentosa rhinitis, illicit intranasal drug abuse, systemic disease, pregnancy, and systemic steroid medication within 4 weeks preceding the enrolment in the study were exclusion criteria.

Continuation of topical nasal steroids was the only concomitant treatment authorised during the study.

The first investigator (N.D.) offered the study to the patients. Informed written consent was obtained from the patient. An independent colleague, not involved in the study, performed the randomization and kept the code until completion of the study. The department secretary wrote on the Investigators Brochure the treatment allocation as $A$ or $B$ and set the treatment modality ( $\mathrm{A}$ or $\mathrm{B}$ ) on the Rhinolight device. The second investigator (N.G.) provided the treatment. At the end of the treatment, the first investigator with help of the laboratory technician collected the outcome measures. The code of the randomisation was opened only at the completion of the study by the promoter (C.H.). After enrolment in the study, 50 patients were randomly allocated to two treatments: mixed visible light, UVA and UVB (mUV/ Vis) or placebo consisting of low-intensity visible light (I-Vis). 


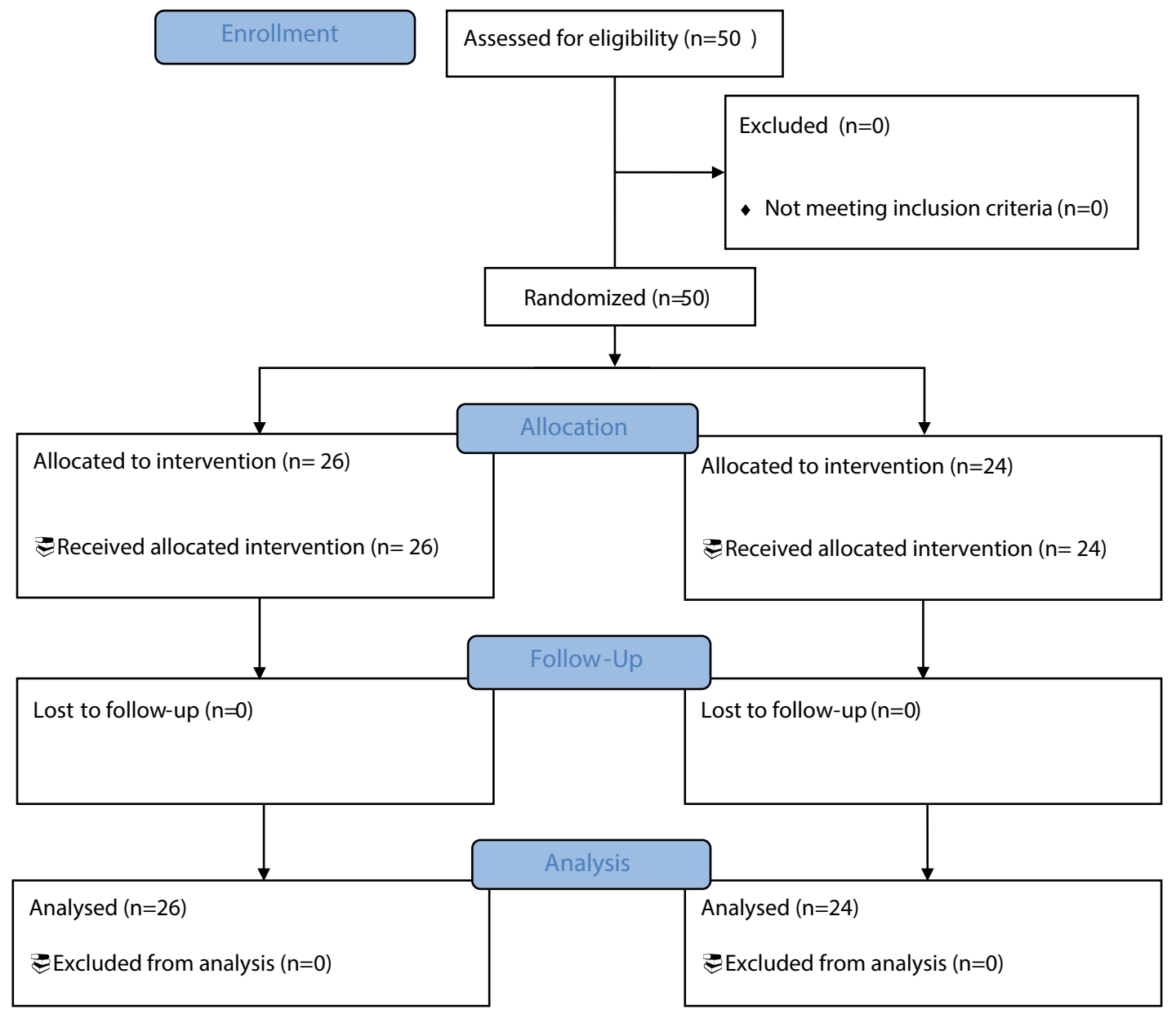

Figure 1. The Consolidated Standards of Reporting Trials (CONSORT) flowchart.

Delivery of the treatment was applied with the same technique and instrument in both groups. It consisted in the administration of a light beam through flexible tubing with a nasal adapter attached to the outlet of the tubing. After entering the nose with the nasal adapter, rotatory movements were performed during illumination of the nose ensuring that a maximal surface of nasal mucosa was illuminated. Delivery of the treatment was operated by a light source named Rhinolight ${ }^{\mathrm{TM}}$ (Rhinolight Ltd, Szeged, Hungary. Range 310-600 nm.) The detergent treated, washed and disinfected (Hibitane ${ }^{\circledR}$ ) metal nasal adapter was fitted on the outlet before each treatment session, filtering (placebo) or not the 310-600 nm light spectrum (phototreatment), with an identical appearance except for an internal colour mark. The outlet was disinfected with chlorhexidine in alcoholic solution (Hibitane ${ }^{\oplus}$ ) before and after each treatment session. Multiple nasal adaptors were delivered with the Rhinolight device. Patients and any persons present in the room during rhinophototherapy carried protective eye glasses. Irradiation time started at 2 minutes and was increased by 25 seconds every two sessions until obtaining a 3 minutes exposure time. Dose ranged from $1.6 \mathrm{~J} / \mathrm{cm}^{2}$ to $2.6 \mathrm{~J} / \mathrm{cm}^{2}$ per session in the $\mathrm{mUV} / \mathrm{Vis}$ group and was limited to $0.06 \mathrm{~J} / \mathrm{cm}^{2}$ in I-Vis group. Irradiation was performed 3 times a week for 3 weeks.

\section{Outcome measures \\ Ratings}

The efficacy of the intranasal phototherapy was evaluated with patient-reported outcomes measures (PROMS) and laboratory objective tests. PROMS included visual analog scales (VAS) for nasal obstruction, sense of smell, rhinorrhea, and facial pain, with ranges from 0 to 10,10 being maximal symptoms. Healthrelated quality of life was assessed with the Rhinosinusitis disability index (RSDI), a quantitative psychometric test, whose reliability, validity and responsiveness were demonstrated in CRS ${ }^{(16-18)}$. RSDI investigates physical, functional and emotional domains and is based on the use of a 5-point Likert scale ranging from never (scored as 0 ) to always (scored as 4). Because a validated translated RSDI version is lacking in French, answer modality was simplified from 0-4 to simple dichotomous answers. A difference of $0.5 \times$ standard deviation (SD) was conside- 
red as the minimally important clinical change for PROMS.

\section{Rhinomanometry}

We measured unilateral nasal resistance through anterior active rhinomanometry before and after vasoconstriction. This was obtained from unilateral recording with Rhinomanometer $300^{\mathrm{Tm}}$ (Atmos AG, Lenzkirch, Germany) at 150 pa after 15 minutes rest. Total nasal resistance (tNR) was calculated according to the equation $1 /(R$ (total $))=1 /(r$ (left $))+1 /(r$ (right)). Normative values for $t N R$ are $0.1-0.4 \mathrm{~Pa} / \mathrm{cm}^{3} / \mathrm{s}$ for congested nasal mucosa and $0.1-0.27 \mathrm{~Pa} / \mathrm{cm}^{3} / \mathrm{s}$ after vasonconstriction with xylomethazoline hydrochloride $1 \%, 1$ push of $0.14 \mathrm{ml}$ per side ${ }^{(19)}$. We calculated the difference between tNR before and after vasonconstriction as a marker of the impact of nasal mucosa congestion to total nasal resistance.

\section{Nasal nitric oxide and carbon monoxide}

Nasal nitric oxide production ( $\mathrm{nNO}$ ) was measured as a noninvasive marker of CRS response to intranasal phototherapy (20). Sampling was obtained through chemiluminescence analysis of nNO production (CLD 77AM Eco Physics ${ }^{\text {TM }}$, Duernten, Switzerland). During nNO sampling, the patient held his breath, to avoid lower airways NO contamination, until the $\mathrm{nNO}$ trace reached a plateau. The mean of three recordings was used with units being particles per billion (ppb) and normal range 200-2000 ppb nNO. Carbon monoxide (CO) in exhaled air was measured with the use of an infrared analyser (Fisher Rosemount NGA 2000 ${ }^{\mathrm{TM}}$, Hasselroth, Germany). Measurements were repeated three times, averaged, and reported in particles per million $(\mathrm{ppm})^{(21)}$.

\section{Olfactory function}

Olfactory function was assessed by means of a standardized psychophysical test “Sniffin' Sticks. We restricted the olfactory testing to threshold determination, since it reflects best the peripheral part olfactory function. These were obtained using a 3-alternative forced-choice task and a staircase paradigm using triplets of pens (Burghart Messtechnik GmbH, Wedel, Germany) one pen with odorant and two blank pens for each dilution step (22).

PROMS and objective measures were measured within a week prior start of treatment (T0), immediately after completion of treatment (T1) and 4 weeks after completion of treatment (T2). The results were adjusted to baseline, consisting in subtracting or adding the difference between both groups at T0, from the obtained results at $\mathrm{T} 1$ and $\mathrm{T} 2$.

\section{Sample size and statistical analysis}

44 patients are required to have a $90 \%$ chance of detecting, as significant at the $5 \%$ level, a decrease of modified RSDI from 0.5 in the control group to 0.3 in the experimental group assuming
Table 1. Mean and standard deviation of patient's characteristics, PROMS and objectives measures at baseline (TO).

\begin{tabular}{|c|c|c|c|}
\hline & $\begin{array}{l}\text { Treatment } \\
\qquad(\mathrm{N}=26)\end{array}$ & $\begin{array}{l}\text { Placebo } \\
(\mathrm{N}=24)\end{array}$ & $\mathbf{p}$ \\
\hline Sex (male) & $46.2 \%$ & $45.8 \%$ & 1.00 \\
\hline Age & $\begin{array}{c}45.00 \\
(11.12)\end{array}$ & $\begin{array}{c}43.13 \\
(12.84)\end{array}$ & 0.49 \\
\hline Disease duration & $8.36(8.25)$ & $9.47(7.11)$ & 0.74 \\
\hline \multicolumn{4}{|l|}{ PROMS } \\
\hline Quality of life (RSDI score) & $0.60(0.26)$ & $0.61(0.18)$ & 0.85 \\
\hline Nasal obstruction VAS & $5.92(2.52)$ & $6.04(2.53)$ & 0.63 \\
\hline Sense of smell VAS & $4.28(3.30)$ & $5.00(3.16)$ & 0.46 \\
\hline Rhinorrhea VAS & $6.68(3.02)$ & $6.30(3.27)$ & 0.71 \\
\hline Facial pain VAS & $5.00(3.52)$ & $5.17(3.55)$ & 0.80 \\
\hline \multicolumn{4}{|l|}{ Objective measures } \\
\hline Total nasal resistance & $1.15(1.25)$ & $0.55(0.22)$ & 0.03 \\
\hline $\begin{array}{l}\text { Total nasal resistance after } \\
\text { vasoconstrictor }\end{array}$ & $0.71(0.70)$ & $0.41(0.22)$ & 0.049 \\
\hline $\begin{array}{l}\text { Difference in total nasal } \\
\text { resistance before and after } \\
\text { vasoconstrictor }\end{array}$ & $0.43(0.92)$ & $0.14(0.13)$ & 0.12 \\
\hline $\begin{array}{l}\text { Olfactory threshold } \\
\text { (out of } 16 \text { ) }\end{array}$ & $7.63(3.08)$ & $7.25(2.59)$ & 0.69 \\
\hline $\begin{array}{l}\text { Nitric oxide production } \\
\text { (ppb) }\end{array}$ & $\begin{array}{c}669.20 \\
(368.87)\end{array}$ & $\begin{array}{c}620.52 \\
(349.66)\end{array}$ & 0.65 \\
\hline $\begin{array}{l}\text { Carbon monoxide produc- } \\
\text { tion (ppm) }\end{array}$ & $4.43(4.26)$ & $5.07(4.99)$ & 0.60 \\
\hline
\end{tabular}

a standard deviation of $0.2^{(23)}$. Baseline characteristics were compared across treatment groups using Fisher exact tests for dichotomous outcomes and Wilcoxon signed rank test for continuous outcomes. The effect of the treatment on each outcome was examined using ANCOVA with baseline value and treatment group as the predictors. Analyses were done using SPSS 18.0. Statistical analysis was performed independently by the statistical department from Geneva University Hospital. Statistician was blinded to treatment allocation. The study was approved by the Geneva University Hospital ASPIC ethic committee (05-129 NAC 05-045). The Consolidated Standards of Reporting Trials (CONSORT) flowchart (Figure 1) and checklist (Appendix 1) were followed.

\section{Results}

Among the 50 patients enrolled in the study, 26 received mUV/ Vis (treatment group) and 24 had the I-Vis (placebo group). The disease duration was 8.36 years in the treatment group and 
Table 2. Means and difference between groups just after treatment (T1) adjusted for same outcome at baseline.

\begin{tabular}{|c|c|c|c|c|}
\hline Outcome & $\begin{array}{l}\text { Mean } \\
\text { Treat- } \\
\text { ment }\end{array}$ & $\begin{array}{c}\text { Mean } \\
\text { Placebo }\end{array}$ & $\begin{array}{l}\text { Diffe- } \\
\text { rence }\end{array}$ & p-value \\
\hline \multicolumn{5}{|l|}{ PROMS } \\
\hline $\begin{array}{l}\text { Quality of life (RSDI } \\
\text { score) }\end{array}$ & 0.71 & 0.72 & -0.01 & 0.84 \\
\hline Nasal obstruction VAS & 4.87 & 4.56 & 0.31 & 0.63 \\
\hline Sense of smell VAS & 3.78 & 4.25 & -0.47 & 0.54 \\
\hline Rhinorrhea VAS & 5.56 & 4.18 & 1.38 & 0.09 \\
\hline Facial pain VAS & 3.76 & 3.18 & 0.58 & 0.43 \\
\hline \multicolumn{5}{|l|}{ Objective measures } \\
\hline Total nasal resistance & 0.65 & 0.67 & -0.02 & 0.88 \\
\hline $\begin{array}{l}\text { Total nasal resistance } \\
\text { after vasoconstrictor }\end{array}$ & 0.56 & 0.44 & 0.12 & 0.40 \\
\hline $\begin{array}{l}\text { Difference in total } \\
\text { nasal resistance before } \\
\text { and after vasocon- } \\
\text { strictor }\end{array}$ & 0.09 & 0.24 & -0.15 & 0.21 \\
\hline $\begin{array}{l}\text { Olfactory threshold } \\
\text { (out of 16) }\end{array}$ & 7.36 & 7.62 & -0.26 & 0.68 \\
\hline $\begin{array}{l}\text { Nitric oxide production } \\
(\mathrm{ppb})\end{array}$ & 571.45 & 656.85 & -85.40 & 0.21 \\
\hline $\begin{array}{l}\text { Carbon monoxide } \\
\text { production (ppm) }\end{array}$ & 5.24 & 3.88 & 1.35 & 0.048 \\
\hline
\end{tabular}

Table 3. Means and difference between groups one month after treatment (T2) adjusted for same outcome at baseline.

$\begin{array}{llll}\text { Mean } & \text { Mean } & \text { Diffe- } \\ \text { Outcome } & \text { Treat- } & \text { Placebo } & \text { rence } \\ \text { ment } & & \end{array}$

\section{PROMS}

\begin{tabular}{|lcccc|}
$\begin{array}{l}\text { Quality of life (RSDI } \\
\text { score) }\end{array}$ & 0.71 & 0.71 & 0.00 & 0.96 \\
\hline $\begin{array}{l}\text { Nasal obstruction VAS } \\
\text { Sense of smell VAS }\end{array}$ & 5.51 & 4.32 & 1.19 & 0.17 \\
\hline Rhinorrhea VAS & 5.09 & 3.94 & 0.15 & 0.85 \\
\hline Facial pain VAS & 4.01 & 4.16 & 0.91 & 0.26 \\
\hline
\end{tabular}

\section{Objective measures}

\begin{tabular}{lcccc}
\hline Total nasal resistance & 0.71 & 0.61 & 0.10 & 0.38 \\
$\begin{array}{l}\text { Total nasal resistance } \\
\text { after vasoconstrictor }\end{array}$ & 0.51 & 0.47 & 0.04 & 0.31 \\
$\begin{array}{l}\text { Difference in total } \\
\text { nasal resistance before } \\
\text { and after vasocon- }\end{array}$ & 0.16 & 0.18 & -0.02 & 0.84 \\
strictor & 7.92 & 7.74 & 0.18 & 0.76 \\
$\begin{array}{l}\text { Olfactory threshold } \\
\text { (out of 16) }\end{array}$ & 530.72 & 632.53 & -101.81 & 0.17 \\
$\begin{array}{l}\text { Nitric oxide production } \\
\text { (ppb) }\end{array}$ & 5.25 & 4.07 & 1.18 & 0.13 \\
$\begin{array}{l}\text { Carbon monoxide } \\
\text { production (ppm) }\end{array}$ & & & & \\
\hline
\end{tabular}

9.47 in the placebo group. All patients completed the study. The PROMS and objective measures at baseline were similar between both groups, except for total nasal resistance without or with vasoconstrictor which were significantly higher in the treatment group (Table 1). Nevertheless, the difference in tNR did not reach statistical difference, emphasizing the homogeneity of both groups. Olfactory thresholds and nasal NO values were within normal limits. Regarding CO values within exhaled air, which is known to be produced in the upper airway, no information could be drawn as their clinical signification is not fully understood.

PROMS and objectives measures, after adjustment to baseline values, just after treatment (Table 2) were similar in both groups, with no significant difference except for $\mathrm{CO}$ production which was higher in the treatment group. Rhinorhea showed a tendency to be worse for treatment group at $\mathrm{T} 1$ without reaching statistical significance. At one month after treatment (T2) neither PROMS nor objectives measures exhibited any difference (Table 3). Side effects were not different between groups (data not shown).

\section{Discussion}

This is the first study to our knowledge investigating the efficacy of intranasal phototherapy in a randomized, blinded and placebo-controlled way. The data only apply to CRS without nasal polyps but clearly show that this treatment is not significantly better than placebo treatment. Although we did not monitor output measurements such as cytokines or histological features, the clinical and psychophysical as well as objective measures do not show any significant effect of rhinophototherapy on PROMS or any other output measurement. These findings are in contradiction to previous studies which presented rhinophototherapy as a valid medical alternative in the treatment of allergic rhinitis ${ }^{(10,24)}$ and perennial allergic rhinitis to house dust mites (25). In addition, a pilot study on narrow-band UVB phototherapy on 13 patients suffering from CRSwNP showed an improvement in PROMS in 10 patients ${ }^{(11)}$. However, a double-blind, placebocontrolled grass pollen challenge study, conducted outside 
of the pollen season failed to demonstrate a benefit from the treatment. In addition to symptom scores, they measured ECP concentration, peak inspiratory and peak expiratory flow with no significant difference between groups after treatment ${ }^{(26)}$. Four hypotheses could explain the negative results of our study. First, the treatment delivery protocol could be one explanation for the present negative results. In a narrow-band UVB phototherapy pilot study on nasal polyps, the treatment against the nasal polyps was delivered under endoscopic visualisation (11). In patients with previous surgery, and therefore better access to the ostiomeatal complex, a better improvement was noticed. None of our patient had previous sinus surgery.

Second, it is possible that the delivered dose in our study was not sufficient to initiate biological effects in CRSsNP. In an ex vivo study on human nasal polyps, the dose-response ratio of apoptotic surface epithelial cells/100 cells and of subepithelial apoptotic leukocytes $/ \mathrm{mm}^{2}$ to single dose of $\mathrm{mUV} / \mathrm{Vis}$ was examined: the number of epithelial apoptotic cells $/ 100$ cells increased from 4.17 (control group) to $15.47\left(3 \mathrm{~J} / \mathrm{cm}^{2}\right), 17.58$ $\left(6 \mathrm{~J} / \mathrm{cm}^{2}\right)$, and $23.78\left(12 \mathrm{~J} / \mathrm{cm}^{2}\right)$, while subepithelial apoptotic leukocytes $/ \mathrm{mm}^{2}$ increased from 8.89 in the control group to $17.94\left(3 \mathrm{~J} / \mathrm{cm}^{2}\right), 25.42\left(6 \mathrm{~J} / \mathrm{cm}^{2}\right)$, and $20.9\left(12 \mathrm{~J} / \mathrm{cm}^{2}\right)^{(27)}$. In another study, biopsy of nasal mucosa was performed before and after rhinophototherapy. Despite clinical benefit of the treatment, the authors were unable to find a statistically significant difference in either morphological changes or in the numbers of dendritic cells, T lymphocytes (CD3+), T helper cell subset (CD4+), and T suppressor cells (CD8+) in the nasal mucosa before and after rhinophototherapy ${ }^{(28)}$. By analogy with dermatological external phototherapy where a single irradiation with UVA and UVB at a dose of $40 \mathrm{~J} / \mathrm{cm}^{2}$ reduces the number of Langerhans cells in the epidermis and leads to morphological changes, the cumulative dose of $20,925 \mathrm{~J} / \mathrm{cm}^{2}$ UVA and $0.418 \mathrm{~J} / \mathrm{cm}^{2}$ UVB delivered to the nasal mucosa might not be sufficient. We deliberately excluded patients with polyps, as we hypothesized that mUV/Vis rhinophtotherapy could not penetrate the thickness of the polyps. Third, it is more likely that the targeted cells and the decrease in IL-5 cytokine observed to respond to rhinophototherapy in allergic rhinitis do not play a major role in CRSsNP pathophysiology. Until further information at cellular and inflammatory level is identified in future research on CRSsNP population and rhinophototherapy, we should not regard rhinophototherapy as a treatment option for this phenotype.

Finally, it is probably not appropriate to rely on the sole clinical diagnosis of CRSsNP to identify a homogenous patient group. The inflammatory mechanisms involved in the pathophysiology of CRSsNP do not exhibit a consistent phenotype as in allergic rhinitis or CRSwNP. We hope further research will identify subtleties in the inflammatory mechanisms among the patient with CRSsNP, refining the potential targeted therapies to homogeneous study population.

\section{Conclusion}

Rhinophototherapy failed to improve PROM and objectives scores in a population of patients with chronic rhinosinusitis without nasal polyposis. Whether selection of the study population, targeted inflammatory cells, treatment delivery modality or phototherapy dose are the reasons for the lack of effect remains to be determined.

\section{Acknowledgements}

To Marianne Hugentobler the laboratory technician who performed the objective tests.

To Anne-Marie Voltolini Machwirth the department secretary, who wrote the treatment allocation and reported the data. The study was self-funded within the department except for the complimentary loan of the Rhinolight device by Rhinolight Ltd (Szeged, Hungary)

\section{Authorship contribution}

ND is the main investigator. He offered the study, collected the outcome measures and wrote the manuscript. NG provided the treatment. DC is the statistician and performed the statistical analysis. BL assisted in the redaction of the manuscript.

JSL provided for the laboratory access and he designed the study protocol. $\mathrm{CH}$ is the promotor and designed the study.

\section{Conflict of interest}

I, Nicolas Dulguerov, the corresponding author, declares on behalf of all authors, that I do not have any conflict of interest in the participation and publication of the results of the present study.

\section{References}

1. Blackwell DL, Collins JG, Coles R. Summary health statistics for U.S. adults: Nationa Health Interview Survey, 1997. Vital Health Stat 10. 2002 May;(205):1-109.

2. Fokkens WJ, Lund VJ, Mullol J, Bachert C, Alobid I, Baroody F, et al. EPOS 2012 European position paper on rhinosinusitis and nasal polyps 2012. A summary for otorhinolaryngologists. Rhinology. 2012
Mar;50(1):1-12.

3. Baguley C, Brownlow A, Yeung K, Pratt E, Sacks R, Harvey R. The fate of chronic rhinosinusitis sufferers after maximal medical therapy. Int Forum Allergy Rhinol. 2014 Jul;4(7):525-32.

4. Fokkens WJ, Lund VJ, Mullol J, et al. European Position Paper on Rhinosinusitis and Nasal Polyps 2012. Rhinol Suppl. 2012 Mar;(23):1-298.
5. Powe DG, Huskisson RS, Carney AS, Jenkins D, Jones NS. Evidence for an inflammatory pathophysiology in idiopathic rhinitis. Clin Exp Allergy. 2001 Jun;31(6):864-72.

6. Van Zele T, Claeys S, Gevaert P, et al. Differentiation of chronic sinus diseases by measurement of inflammatory mediators. Allergy. 2006 Nov;61(11):1280-9.

7. Badia L, Lund V. Topical corticosteroids in nasal polyposis. Drugs. 2001;61(5):573-8. 
8. Anderson TF, Waldinger TP, Voorhees JJ UV-B phototherapy. An overview. Arch Dermatol. 1984 Nov; 120(11):1502-7.

9. Grimes DR. Ultraviolet radiation therapy and UVR dose models. Med Physics. 2015 Jan;42(1):440-55.

10. Matsumura $Y$, Ananthaswamy HN. Toxic effects of ultraviolet radiation on the skin. Toxicol Appl Pharmacol. 2004 Mar 15;195(3):298-308.

11. Koreck Al, Csoma Z, Bodai L, et al. Rhinophototherapy: a new therapeutic too for the management of allergic rhinitis. Allergy Clin Immunol. 2005 Mar;115(3):5417.

12. Bella Z, Kadocsa E, Kemeny L, Koreck A. Narrow-band UVB phototherapy of nasal polyps: results of a pilot study. J Photochem Photobiol B. 2010 Sep 2;100(3):123-7.

13. Lee $E$, Koo J, Berger T. UVB phototherapy and skin cancer risk: a review of the literature. J Photochem Photobiol B. 2010 Sep 2;100(3):123-7.

14. Krutmann J. Phototherapy for atopic dermatitis. Clin Exp Dermatol. 2000 Oct;25(7):552-8.

15. Lim JL, Stern RS. High levels of ultraviolet B exposure increase the risk of non-melanoma skin cancer in psoralen and ultraviolet A-treated patients. J Invest Dermatol. 2005 Mar;124(3):505-13.

16. Mitchell D, Paniker L, Sanchez G, et al. Molecular response of nasal mucosa to therapeutic exposure to broad-band ultraviolet radiation. J Cell Mol Med. 2010 Jan; 14(1-2):313-22.

17. Benninger MS, Senior BA. The development of the Rhinosinusitis Disability Index.
Arch Otolaryngol Head Neck Surg. 1997 Nov;123(11):1175-9.

18. Chen H, Katz PP, Shiboski S, Blanc PD. Evaluating change in health-related quality of life in adult rhinitis: responsiveness of the Rhinosinusitis Disability Index. Health Qual Life Outcomes. 2005 Nov 8;3:68.

19. Quintanilla-Dieck L, Litvack JR, Mace JC, Smith TL. Comparison of disease-specific quality-of-life instruments in the assessment of chronic rhinosinusitis. Int Forum Allergy Rhinol. 2012 Nov;2(6):437-43.

20. Merkle J, Kohlhas L, Zadoyan G, Mosges R, Hellmich M. Rhinomanometric reference intervals for normal total nasal airflow resistance. Rhinology. 2014 Dec;52(4):292-9.

21. Ragab SM, Lund VJ, Saleh HA, Scadding G. Nasal nitric oxide in objective evaluation of chronic rhinosinusitis therapy. Allergy. 2006 Jun;61(6):717-24.

22. Andersson JA, Uddman R, Cardell LO Carbon monoxide is endogenously produced in the human nose and paranasal sinuses. J Allergy Clin Immunol. 2000 Feb;105(2 Pt 1):269-73.

23. Hummel T, Kobal G, Gudziol H, Mackay-Sim A. Normative data for the "Sniffin' Sticks" including tests of odor identification, odor discrimination, and olfactory thresholds: an upgrade based on a group of more than 3,000 subjects. Eur Arch Otorhinolaryngol. 2007 Mar;264(3):237-43.

24. Senior BA, Glaze C, Benninger MS. Use of the Rhinosinusitis Disability Index (RSDI) in rhinologic disease. Am J Rhinol. 2001 JanFeb;15(1):15-20

25. Cingi C, Cakli H, Yaz A, Songu M, Bal C. Phototherapy for allergic rhinitis: a prospec- tive, randomized, single-blind, placebocontrolled study. Ther Adv Respir Dis. 2010 Aug;4(4):209-13.

26. Tatar EC, Korkmaz H, Surenoglu UA, Saylam G, Ozdek A. Effects of rhinophototherapy on quality of life in persistant allergic rhinitis. Clin Exp Otorhinolaryngol. 2013 Jun;6(2):73-

27. Emberlin JC, Lewis RA. Pollen challenge study of a phototherapy device for reducing the symptoms of hay fever. Curr Med Res Opin. 2009 Jul;25(7):1635-44.

28. Nemeth IB, Zsiros O, Koreck A, et al. Ultraviolet light and photodynamic therapy induce apoptosis in nasal polyps. J Photochem Photobiol B. 2012 Dec 5;117:179-84.

29. Brehmer D, Schon MP. Endonasal phototherapy significantly alleviates symptoms of allergic rhinitis, but has a limited impact on the nasal mucosal immune cells. Eur Arch Otorhinolaryngol. 2011 Mar;268(3):393-9.

\section{Nicolas Dulguerov}

Otorhinolaryngology, Head and Neck

Surgery Department

4, rue Gabrielle-Perret-Gentil

1205 Geneva

Switzerland

Tel: +41 (0)22372 8268

Fax: +41 (0)22 3728240

E-mail: Nicolas.dulguerov@hcuge.ch 